\title{
New Treatment Approaches in Chronic Kidney Disease-associated Anaemia
}

\author{
Lucia Del Vecchio ${ }^{1}$ and Francesco Locatelli²
}

1. Clinical Staff Member; 2. Head, Department of Nephrology, Dialysis, and Renal Transplant, 'Alessandro Manzoni' Hospital

\begin{abstract}
Recombinant human erythropoietin (rHUEPO) is an effective agent for the treatment of anaemia in patients with chronic kidney disease. However, given its relatively short half-life, it requires a relatively frequent administration schedule. Moreover, it can be administered only subcutaneously or intravenously and is unstable at room temperature, making a strict cold chain control necessary. Pharmacological research has focused on the development of new agents to circumvent these relative disadvantages. Some long-acting erythropoietin-stimulating agents (ESAS) are already available for clinical use that require a less-frequent administration schedule. Peginesatide (Hematide ${ }^{\mathrm{TM}}$ ), which is a small dimeric peptide with a chemical structure unrelated to EPO, has recently ended phase III clinical trials. Other new molecules undergoing clinical development are CNTO 530 and CNTO 528, ACE-011 and hypoxia-inducible transcription factor stabilisers. The latter have the advantage that they can be administered orally but their clinical development faces a significant hurdle following a case of fatal hepatitis. Newer molecules in this class are undergoing clinical evaluation. Other strategies, such as EPO fusion proteins, agonistic antibodies targeting the EPO receptor and gene therapy have only been tested in animal models or are undergoing pre-clinical evaluations. Before clinical approval, all these new strategies need to address safety concerns raised recently about the use of ESAs regarding possible increased cardiovascular risks following targeting to high haemoglobin levels and/or exposure to excessive doses without reaching a target in both higher and lower haemoglobin groups, and reduced survival and tumour control in the oncology setting. Many of these molecules will also need careful evaluation for possible immunogenicity.
\end{abstract}

\section{Keywords}

Anaemia, erythropoietin, chronic kidney disease, Hematide $^{\text {TM }}$, prolyl hydroxylase inhibitor, erythropoiesis

Disclosure: Lucia Del Vecchio has no conflicts of interest to declare. Francesco Locatelli is on the advisory boards of Affymax, Amgen-Dompé, GlaxoSmithKline, Janssen Cilag, Roche and Takeda and on the Safety Committee of Sandoz.

Received: 27 August 2010 Accepted: 9 March 2011 Citation: European Oncology \& Haematology, 2011;7(2):132-5 DOI: 10.17925/EOH.2011.07.02.132

Correspondence: Francesco Locatelli, Department of Nephrology, Dialysis, and Renal Transplant, Alessandro Manzoni Hospital, Via dell'Eremo 9, 23900 Lecco, Italy. E: f.locatelli@ospedale.lecco.it

Anaemia, resulting primarily from insufficient production of erythropoietin to support erythropoiesis, is a common complication of chronic kidney disease (CKD). Approximately $50 \%$ of patients with CKD stage III-V have anaemia. ${ }^{1}$ This percentage increases greatly in patients receiving dialysis. ${ }^{2}$ Since the late 1980s, the availability of recombinant human erythropoietin (rHUEPO) has revolutionised the management of anaemia in patients with CKD. Today, erythropoiesisstimulating agents (ESAS), together with iron supplementation, are the main tool used to achieve anaemia correction in CKD patients.

Over the past two decades, several attempts have been made to develop new ESAS with theoretically improved characteristics compared with rHuEPO, to develop easier manufacturing processes and to develop other strategies that may indirectly increase erythropoiesis. Table 1 summarises new ESAs under clinical development in CKD patients.

\section{Erythropoiesis-stimulating Agents - Molecules on the Market}

Epoetin alpha and epoetin beta are synthesised in Chinese hamster ovary cells and share the same amino acid sequence as endogenous EPO but slightly differ in their carbohydrate moieties. ${ }^{3}$ The patent of both drugs expired some years ago, opening the way to biosimilars.
Some of the biosimilars have their own international non-proprietary names (INN) (epoetin zeta), but their molecular structure is close to that of epoetin alpha.

Epoetin theta is similar to epoetin alpha and received marketing approval from the European Medicines Agency (EMA) in 2009 as an originator. Epoetin omega and epoetin delta differ from epoetin alpha and beta because they are synthesised in cells other than those from the Chinese hamster ovary ${ }^{4,5}$ and, consequently, they differ slightly in their glycosylation patterns compared with epoetin alpha and beta. ${ }^{6}$ Epoetin delta was discontinued in 2009 for commercial reasons.

Darbepoetin alpha (Amgen Inc.) is the first EPO analogue with a prolonged half-life. Compared with EPO, it has a modified amino acid sequence, higher sialic acid content and molecular weight, and increased negative charge. ${ }^{7}$ The half-life of darbepoetin alpha is nearly two to three times that of rHuEPO depending on the administration route. This characteristic allows a less-frequent administration schedule. Dose requirements are almost independent of the administration route. ${ }^{8}$

Continuous erythropoietin receptor activator (CERA) (Roche) is another modified EPO molecule containing a large water-soluble 
Table 1: New Erythropoiesis-stimulating Agents Under Clinical Development in Patients with Chronic Kidney Disease According to the Development Phase

\begin{tabular}{|c|c|c|c|c|c|}
\hline Drug & Company & Structure & Mechanism of Action & $\begin{array}{l}\text { Administration } \\
\text { Route }\end{array}$ & $\begin{array}{l}\text { Development } \\
\text { Phase }\end{array}$ \\
\hline $\begin{array}{l}\text { Peginesatide } \\
\left(\text { Hematide }^{\mathrm{TM}}\right)\end{array}$ & $\begin{array}{l}\text { Affymax and } \\
\text { Takeda }\end{array}$ & $\begin{array}{l}\text { Small dimeric peptide + } \\
\text { PEG moiety }\end{array}$ & EPO receptor activation & SC and IV & III \\
\hline ACE-011 & $\begin{array}{l}\text { Acceleron and } \\
\text { Celgene Corporation }\end{array}$ & $\begin{array}{l}\text { Dimeric fusion protein } \\
\text { targeting the TGF- } \beta \text { superfamily }\end{array}$ & $\begin{array}{l}\text { Blocking of the } \\
\text { SMAD pathway }\end{array}$ & SC and IV & Ila \\
\hline FG-2216 & FibroGen & Prolyl hydroxylase inhibitor & EPO gene transcription & $\mathrm{PO}$ & $\begin{array}{l}\text { II, not actively } \\
\text { recruiting }\end{array}$ \\
\hline FG-4592 & FibroGen & Prolyl hydroxylase inhibitor & EPO gene transcription & $\mathrm{PO}$ & II \\
\hline GSK1278863 & GlaxosmithKline & Prolyl hydroxylase inhibitor & EPO gene transcription & PO & 1 \\
\hline CNTO 530 & Ortho Biotech & $\begin{array}{l}\text { Two 20-amino acid peptides } \\
+ \text { human IgG4 FC }\end{array}$ & EPO receptor activation & SC and IV & 1 \\
\hline CNTO 528 & Ortho Biotech & $\begin{array}{l}\text { Two 20-amino acid peptides } \\
\text { + human IgG4 FC human IgG4 FC }\end{array}$ & EPO receptor activation & SC and IV & 1 \\
\hline
\end{tabular}

$E P O=$ erythropoietin; $I g=$ immunoglobulin; $I V=$ intravenous; $P E G=$ polyethylene glycol; $P O=$ oral; $S C=$ subcutaneous; $T G F=$ transforming growth factor .

polyethylene glycol (PEG) moiety. The molecular weight of CERA is nearly double that of EPO and it has a much longer half-life ( 130 hours). ${ }^{9}$ Like darbepoetin alpha, the binding affinity of CERA for the erythropoietin receptor is also reduced but to a far greater extent. This peculiarity may contribute to distinct pharmacological characteristics (it has been hypothesised that the same CERA molecule may activate the EPO receptor several times without being internalised). The dose does not need to be modified according to the administration route.

\section{Erythropoietin Mimetic Peptides}

In 1996, peptides with no sequence homology to EPO but with EPO receptor specificity were identified. ${ }^{10,11}$ However, because of their low molecular mass they were rapidly excreted in urine. A small dimeric peptide was then conjugated to a polyethylene glycol moiety to form a new drug, peginesatide (Hematide ${ }^{\mathrm{TM}}$, Affymax and Takeda), which has a highly specific binding to the EPO receptor, with five-times less binding potency than epoetin or darbepoetin alpha. ${ }^{12}$ Unlike rHuEPO and its analogues, and similar to the first peptides, peginesatide is partially cleared by the kidney. Accordingly, CKD patients needed half the dose of healthy volunteers to achieve similar efficacy. Like other long-acting ESAS, peginesatide pharmacodynamics and dose requirement are irrespective of the administration route. Owing to the fact that peginesatide has a molecular structure unrelated to that of EPO, it was used to correct anaemia in a rat model of antibody-mediated pure red-cell aplasia (PRCA) ${ }^{13}$ and then found to be effective in 13 out of 14 patients with CKD and PRCA. ${ }^{14}$ Phase I and II trials showed a good efficacy and safety profile for the drug in healthy volunteers ${ }^{15}$ and in patients with $\mathrm{CKD}^{16}$ or cancer ${ }^{17}$ when given once a month either intravenously or subcutaneously. In June 2010, Affymax and Takeda announced preliminary results of phase III clinical trials in CKD patients. ${ }^{18}$ The four studies (EMERALD 1, EMERALD 2, PEARL 1 and PEARL 2), which enrolled more than 2,000 patients for a median follow-up of 1.3 years, showed non-inferiority in the mean change in haemoglobin from baseline compared with epoetin and darbepoetin in correcting and/or maintaining haemoglobin in the target range.

Although the combined four studies showed that peginesatide was not inferior to the other ESAs in the risk of cardiovascular composite safety end-points, subgroup analysis of patients not on dialysis found a higher frequency of cardiovascular events in the peginesatide group compared with the other ESAS (21.6 and 17.1\%, respectively; hazard ratio $[\mathrm{HR}] 1.34,90 \%$ confidence interval $[\mathrm{CI}] 1.03-1.73)$. The clinical meaning of this finding is unclear because it is unlikely that a single ESA would increase cardiovascular risk independently from the haemoglobin target, particularly in non-dialysis patients where doses are much lower than in those receiving dialysis. The HR in the non-dialysis patients was primarily driven by higher rates of death, unstable angina and arrhythmia events in the peginesatide group, but these comorbidities are usually more frequent in dialysis than in non-dialysis patients.

Two other non-erythropoietin-derived EPO-receptor agonists have been recently developed by Ortho Biotech Inc. and are undergoing clinical evaluation. Two sequences of a 20-amino acid peptide with weak EPO-like bioactivity (EMP1) were coupled with a human immunoglobulin (Ig) G4 Fc. The molecule obtained, CNTO 530, selectively binds the EPO-receptor. ${ }^{19}$ In animal studies, it is a more potent stimulator of erythropoiesis than epoetin-alpha or darbepoetin alpha..$^{20}$ A similar molecule, CNTO 528, has undergone phase I clinical development. ${ }^{21}$ Single intravenous administration of CNTO 528 at ascending doses (from 0.03 to $0.9 \mathrm{mg} / \mathrm{kg}$ ) stimulated the production of reticulocytes, red blood cells and haemoglobin in 24 healthy volunteers. Similar findings were obtained in another single and fractional ascending dose study of 44 healthy adult volunteers. ${ }^{22}$ Of the ESAs developed to date, CNTO 528 has the longest half-life (four to seven days).

\section{Agonistic Antibodies Targeting the Erythropoietin Receptor}

Mouse monoclonal antibodies against the soluble extracellular domain of the human EPO receptor were developed some years ago. ${ }^{23,24}$ These antibodies mimic EPO activity but activate the EPO receptor poorly. More recently, ABT-007 (Abbott Bioresearch Center) has been developed. ${ }^{25}$ According to data obtained using a transgenic mouse model expressing the human EPO receptor (ABT-007 does not recognise the rodent EPO receptor), this is a potent in vivo stimulator of erythropoiesis requiring less-frequent dosing than darbepoetin alpha. In addition, ABT-007 dosing in transgenic mice resulted in less fluctuation of haematocrit than that observed following darbepoetin dosing. Like other long-acting ESAs, increases in haematocrit were similar following either subcutaneous or intravenous administration of ABT-007. 


\section{Modified Erythropoietin Molecules Under Development}

Attempts have been made to fuse EPO with unrelated peptides, such as human chorionic gonadotropin beta (beta HCG) ${ }^{26}$ or the FC part of an antibody, ${ }^{27}$ which are known to increase the in vivo potency and circulatory half-life of the molecule. This approach has been used to create an Fc fusion protein (Syntonix Pharmaceuticals, Inc) that can be administered by aerosol inhalation..$^{28}$

Albumin is another fusion partner of glycoproteins such as insulin and interferon. Three kinds of albumin-EPO fusion proteins (IALE, AD2LE and AD1LE) have been produced with a similar half-life and in vivo efficacy to that of darbepoetin. ${ }^{29}$

A non-glycosylated denatured EPO was obtained from Escherichia col and then refolded and pegylated..$^{30}$ The final molecule had a lower bioactivity than rHuEPO but enhanced thermal stability and prolonged circulating half-life in rats. The addition of linear PEGs of increasing size and a branched activated PEG (PEG-2, 40kDa) progressively improves pharmacokinetic performances; ${ }^{31}$ the two 40k-PEG conjugates demonstrated comparable in vivo efficacies to that of rHuEPO. However, even if they are effective in correcting anaemia, all these EPO-modified proteins raise some concerns about immunogenicity. ${ }^{32}$

\section{Sotatercept (ACE-011)}

ACE-011 (Acceleron and Celgene Corporation) is a novel drug being developed for the treatment of chemotherapy-induced anaemia. It is a dimeric fusion protein that targets members of the transforming growth factor- $\beta$ superfamily that signal through the activin receptor type IIA (ActRIIA). The drug, consisting of the extracellular domain of the ActRIIA linked to the Fc portion of human IgG1, binds to activin, preventing activin from binding endogenous receptors and interfering with downstream signalling cascades, in particular the SMAD pathway. This pathway promotes hepcidin transcription in hepatocytes and maintains systemic iron homeostasis. ${ }^{33}$ In a phase I clinical trial in post-menopausal females, sotatercept increased haematocrit levels. ${ }^{34}$ The drug also seems to have antitumour activity and promotes new bone formation. ${ }^{35}$

ACE-011 is currently being studied in two phase II clinical trials in cancer patients; a phase Ila, study is also ongoing to test anaemia correction in patients with CKD stage $\mathrm{V}$.

\section{Hypoxia-inducible Transcription Factor Stabilisers}

The hypoxia-inducible transcription factors (HIFs) mediate the effects of hypoxia on the cell. By regulating the expression of a large array of target genes during hypoxia, these proteins also direct adaptive changes in several systems, including the hematopoietic system. Under normal conditions, the HIF $\alpha$ subunit is prolyl hydroxylated and then degraded. Under hypoxia, HIF $\alpha$ accumulates and together with $\mathrm{HIF} \beta$ transcriptionally activates genes such as EPO. The HIF-stabilisers prevent HIF inactivation through alpha hydroxylation and thus stimulate erythropoiesis. These agents have the great advantage that they can be administered orally. The clinical development of FG-2216 (FibroGen, Inc.), the first promising molecule in this class, was halted some years ago following a case of fatal hepatitis. In 2008, phase II clinical trials in dialysis and non-dialysis patients were started with a new agent (FG-4592, FibroGen, Inc.). The preliminary findings of one of these phase II trials were presented at the 2010 annual meeting of the
American Society of Nephrology. ${ }^{36}$ One hundred and seventeen patients with CKD stage III-IV were randomised to either FG-4592 ( $n=88$, four doses escalating from 0.7 to $2 \mathrm{mg} / \mathrm{kg}$ administered two or three times weekly) or placebo $(n=28)$ for four weeks. The haemoglobin responder rate was dose dependent and maximal in those receiving the highest dose three times weekly. For responders, median time to haemoglobin response was 22-43 and 15-22 days for twice and three times weekly administration, respectively. Despite the rapid rate of haemoglobin rise with higher doses compared with that observed with other ESAs, a significant increase in blood pressure was observed in only one patient. No liver toxicity was described. GlaxoSmithKline is developing another prolyl hydroxylase inhibitor (GSK1278863). A single-escalating-dose, phase I clinical trial was concluded in 2009 in healthy individuals. A phase Ila clinical trial is underway to evaluate the safety, pharmacokinetics and efficacy of repeat doses in anaemic patients with CKD (both dialysis and pre-dialysis).

\section{Gene Therapy}

Several techniques have been tried to release a small but continuous amount of EPO into the circulation through EPO gene therapy. ${ }^{37-42}$ Unfortunately, these approaches are not yet used in clinical practice because it appears difficult to exactly tune the amount of EPO needed to correct anaemia, maintaining a level of expression that promotes erythropoiesis in the long term and varies according to clinic needs. Moreover, ex vivo transfected implanted cells may give rise to immunological problems.

\section{PBI-1402}

PBI-1402 (Prometic) is a low-molecular-weight synthetic drug with erythropoiesis-stimulating activity. This compound is orally active and although it mimics the biological activity of EPO, it has a mechanism of action that is distinct from EPO because it does not bind to the same cell surface receptor. In multiple pre-clinical models it has also shown anticancer activity. Phase I studies showed a good safety profile and an increase of reticulocyte counts in healthy volunteers. A phase II trial of PBI-1402 showed a significant increase in haemoglobin levels in patients with chemotherapy-induced anaemia. Recent experiments based on a 5/6 nephrectomised rat model have demonstrated the ability of $\mathrm{PBI}-1402$ to correct anaemia in this setting. These results suggest that this agent could also have a potential use in the treatment of anaemia in patients with CKD, but to date no clinical trials with this compound are under way.

\section{Vitamin E-coated Dialysers}

Oxidative stress may have an independent negative role on anaemia and ESA responsiveness; anecdotal data suggest that oral vitamin E supplementation may improve ESA responsiveness. ${ }^{43}$ Given that blood-membrane interaction plays a key role in generating oxidative stress, direct free-radical scavenging at the membrane site has been proposed. Some studies tested the role of vitamin E-coated membranes on ESA responsiveness. One study found that a significantly higher proportion of patients achieved the recommended haemoglobin target while receiving a lower ESA dose after being shifted from their previous dialyser to a vitamin E-coated membrane. ${ }^{44}$ However, improved ESA responsiveness may also have been caused by enhanced membrane biocompatibility. More recently, a pilot, open, controlled, randomised study of 20 haemodialysis patients compared a synthetic polysulphone dialyser with and without vitamin $\mathrm{E} .{ }^{45} \mathrm{~A}$ clear trend towards a greater decrease in the ESA resistance index (i.e. the ratio between haemoglobin and ESA dose) was found in the vitamin $E$ 
treated group compared with the control group (37 versus 20\%, $p=$ not significant); this difference became statistically significant when analysed using multivariate analysis. Further larger studies need to demonstrate that these membranes have significant positive clinical effects in order to balance high treatment costs.

\section{Conclusion}

RHUEPO has been available to treat anaemia in patients with CKD for the past twenty years. More recently, long-acting rHuEPOs with modified molecular structures have also entered the market offering the advantage of less-frequent administration schedules. All these molecules are effective in correcting anaemia and decreasing transfusion needs. However, the treatment of anaemia with rHuEPO or its analogues is quite expensive, given that their synthesis, like that of other biomolecules, is complex. New ESAs are or will be even more expensive than rHuEPO because of the high costs of the pharmacological research, which has not yet been covered by years of selling. Moreover, safety concerns have been raised recently about the use of ESAs that may be associated with increased cardiovascular risks following targeting to high haemoglobin levels and/or exposure to excessive doses ${ }^{46}$ and reduced survival and tumour control in the oncology setting. ${ }^{47}$ This will entail additional requirements to be fulfilled by the drugs under development before clinical approval, which will further increase costs. However, the synthesis of simpler molecules not related to ESA structure may lead to the creation of cheaper ESAs that would revolutionise the market. In this respect, peginesatide seems to be the most promising in the near future. CNTO 530 and CNTO 528, two non-erythropoietin derived EPO-receptor agonists, are also under clinical development. Given their long half-life, they are likely to be administered less frequently than peginesatide. In the meantime, biosimilars of rHuEPO have entered the market in many European countries and compete economically with the originator or long-acting ESAS.

New approaches to stimulate erythropoiesis will not only need to be effective and safe, but will also need to be a substantial improvement on rHuEPO or other available ESAs, or be cheaper thanks to the development of simpler manufacturing processes.
1. McClellan WM, Aronoff SL, Bolton WK, The prevalence of anaemia in patients with chronic kidney disease, Curr Med Res Opin, 2004;20:1501-10

2. Locatelli F, Pisoni RL, Combe C, et al., Anaemia in haemodialysis patients of five European countries: association with morbidity and mortality in the Dialysis Outcomes and Practice Patterns Study (DOPPS), Nephrol Dial Transplant, 2004;19:121-32.

3. Storring PL, Tiplady RJ, Gaines Das RE, et al., Epoetin alfa and beta differ in their erythropoietin isoform compositions and beta differ in their erythropoietin isoform compositon
biological properties, Br J Haematol, 1998;100:79-89.

4. Powell JS, Berkner KL, Lebo RV, et al., Human erythropoietin gene: high level expression in stably transfected mammalian cells and chromosome localization, Proc Natl Acad Sci U S A, 1986;83:6465-9.

5. Kwan JT, Pratt RD, The Epoetin Delta Study Group, Epoetin delta, erythropoietin produced in a human cell line, in the management of anaemia in predialysis chronic kidney disease patients, Curr Med Res Opin, 2007;23:307-11.

6. Nimtz M, Martin W, Wray V, et al., Structures of sialylated oligosaccharides of human erythropoietin expressed in recombinant BHK-21 cells, Eur J Biochem, 1993;213:39-56.

7. Egrie JC, Browne KJ, Development and characterisation of novel erythropoiesis stimulating protein (NESP), Nephrol Dial Transplant, 2001;16(Suppl. 3):3-13.

8. Locatelli F, Canaud B, Giacardy F, et al., Treatment of anaemia in dialysis patients with unit dosing of darbepoetin alfa at a reduced dose frequency relative to recombinant human erythropoietin (rHuEpo), Nephrol Dial Transplant, 2003;18:362-9.

9. Chanu P, Gieschke R, Charoin JE, et al., Population pharmacokinetic/pharmacodynamic model for C.E.R.A. in both ESA-naive and ESA-treated chronic kidney disease patients with renal anemia, J Clin Pharmacol, 2010;50:507-20.

10. Livnah $\mathrm{O}$, Stura EA, Johnson DL, et al., Functional mimicry of a protein hormone by a peptide agonist: the EPO receptor complex at 2.8 A, Science, 1996;273:464-71

11. Wrighton NC, Farrell FX, Chang R, et al., Small peptides as potent mimetics of the protein hormone erythropoietin, Science, 1996;273:458-64.

12. Fan $\mathrm{Q}$, Leuther $\mathrm{KK}$, Holmes $\mathrm{CP}$, et al., Preclinical evaluation of Hematide, a novel erythropoiesis stimulating agent, for the treatment of anemia, Exp Hematol, 2006:34:1303-11.

13. Woodburn KW, Fan Q, Winslow S, et al., Hematide is immunologically distinct from erythropoietin and corrects anemia induced by antierythropoietin antibodies in a rat pure red cell aplasia model, Exp Hematol, 2007;35:1201-8.

14. Macdougall IC, Rossert J, Casadevall N, et al., A peptidebased erythropoietin-receptor agonist for pure red-cell aplasia, N Engl J Med, 2009;361:1848-55.

15. Stead RB, Lambert J, Wessels D, et al., Evaluation of the safety and pharmacodynamics of Hematide, a novel erythropoietic agent, in a phase 1, double-blind, placeboerythropoietic agent, in a phase 1, double-blind, placebo-
controlled, dose-escalation study in healthy volunteers, Blood 2006;108:1830-4.

16. Besarab A, Zeig S, Geronemus R, et al., Hematide, a synthetic peptide-based erythropoiesis stimulating agent, maintains hemoglobin in hemodialysis patients previously treated epoetin alfa (erythropoietin). Presented at the Nationa Kidney Foundation Spring Clinical Meeting, Orlando, FL, 10-14 April 2007.
17. Pickering LM, Cwiertka K, Jassem J, et al., Hematide, a synthetic peptide-based erythropoiesis stimulating agent (ESA), assessed for correction of anemia in oncology patients receiving chemotherapy, Blood, 2006;108:378a.

18. Affymax and Takeda announce phase 3 trials meet primary endpoints for investigational drug, Hematide ${ }^{\mathrm{TM}}$ /peginesatide to treat anemia in chronic renal failure with some differences noted in secondary analyses. Available at: www.investors .affymax.com/releasedetail.cfm?ReleaselD=481068 (accessed 5 November 2010).

19. Bugelski PJ, Capocasale RJ, Makropoulos D, et al., CNTO 530: molecular pharmacology in human UT-7EPO cells and pharmacokinetics and pharmacodynamics in mice J Biotechnol, 2008;134:171-80.

20. Sathyanarayana P, Houde E, Marshall D, et al., CNTO 530 functions as a potent EPO mimetic via unique sustained effects on bone marrow proerythroblast pools, Blood, 2009:113:4955-62.

21. Pérez-Ruixo JJ, Krzyzanski W, Bouman-Thio E, et al. Pharmacokinetics and pharmacodynamics of the erythropoietin Mimetibody construct CNTO 528 in healthy subjects, Clin Pharmacokinet, 2009:48:601-13.

22. Bouman-Thio E, Franson $K$, Miller $B$, et al., A phase I, single and fractionated, ascending-dose study evaluating the safety, pharmacokinetics, pharmacodynamics, and immunogenicity of an erythropoietin mimetic antibody fusio protein (CNTO 528) in healthy male subjects, I Clin Pharmacol, 2008;48:1197-207.

23. Schneider H, Chaovapong W, Matthews DJ, et al., Homodimerization of erythropoietin receptor by a bivalent monoclonal antibody triggers cell proliferation and differentiation of erythroid precursors, Blood, 1997;89:473-82.

24. Elliott S, Lorenzini T, Yanagihara D, et al., Activation of the erythropoietin (EPO) receptor by bivalent anti-EPO receptor antibodies, J Biol Chem, 1996;271:24691-7.

25. Liu Z, Stoll VS, Devries PJ, et al., A potent erythropoietinmimicking human antibody interacts through a novel binding site, Blood, 2007;110:2408-13.

26. Fares F, Ganem S, Hajouj T, Agai E, Development of a longacting erythropoietin by fusing the carboxyl-terminal peptide of human chorionic gonadotropin beta-subunit to the coding of human chorionic gonadotropin beta-subunit sequence of hum

27. Schriebl K, Trummer E, Lattenmayer $\mathrm{C}$, et al., Biochemical characterization of rhEpo-Fc fusion protein expressed in $\mathrm{CHO}$ cells, Protein Expr Purif, 2006;49:265-75.

28. Dumont JA, Bitonti AJ, Clark D, et al., Delivery of an erythropoietin-Fc fusion protein by inhalation in humans through an immunoglobulin transport pathway, I Aerosol Med, 2005;18:294-303.

29. Joung $\mathrm{CH}$, Shin JY, Koo JK, et al., Production and characterization of long-acting recombinant human albuminEPO fusion protein expressed in CHO cell, Protein Expr Purif, 2009;68:137-45.

30. Wang YJ, Liu YD, Chen J, et al., Efficient preparation and PEGylation of recombinant human non-glycosylated erythropoietin expressed as inclusion body in E. coll, Int J Pharm, 2010;386:156-64

31. Wang YJ, Hao SJ, Liu YD, et al., PEGylation markedly enhances the in vivo potency of recombinant human nonglycosylated erythropoietin: a comparison with glycosylated erythropoietin, I Control Release, 2010:145:306-13.

32. Coscarella $A$, Liddi $R$, Di Loreto $M$, et al., The rhGM-CSF-EPO hybrid protein MEN 11300 induces anti-EPO antibodies and severe anaemia in rhesus monkeys, Cytokine, 1998;10:964-9.

33. Finberg KE, Whittlesey RL, Fleming MD, Andrews NC, Downregulation of Bmp/Smad signaling by Tmprss 6 is required for maintenance of systemic iron homeostasis, Blood, 2010;115:3817-26.

34. Ruckle J, Jacobs M, Kramer W, et al., Single-dose randomized, double-blind, placebo-controlled study of ACE-011 (ActRIIA-IgG1) in postmenopausal women, Bone Miner Res, 2009:24:744-52.

35. Raje N, Vallet S. Sotatercept, a soluble activin receptor typ 2A IgG-FC fusion protein for the treatment of anemia and bone loss, Curr Opin Mol Ther, 2010;12:586-97.

36. Besarab A, Hulter HN, Klaus S, et al., FG-4592, a novel ora HIF prolyl hydroxylase inhibitor, elevates hemoglobin in anemic stage 3/4 CKD patients. American Society of Nephrology Renal Week 2010; Denver, CO, USA, 16-2 November 2010. Abstract SA-FC416.

37. Sebestyén MG, Hegge JO, Noble MA, et al., Progress toward a nonviral gene therapy protocol for the treatment of anemia, Hum Gene Ther, 2007;18:269-85.

38. Fattori E, Cappelletti M, Zampaglione I, et al., Gene electrotransfer on an improved erythropoietin plasmid in mice and non-human primates, J Gene Med, 2005;7:228-36.

39. Eliopoulos N, Gagnon RF, Francois M, Galipeau J, Erythropoietin delivery by genetically engineered bone marrow stromal cells for correction of anemia in mice with chronic renal failure, J Am Soc Nephrol, 2006;17:1576-84.

40. Oh TK, Quan GH, Kim HY, et al., Correction of anemia in uremic rats by intramuscular injection of lentivirus carrying an erythropoietin gene, Am J Nephrol, 2006;26:326-34.

41. Kakeda M, Hiratsuka M, Nagata K, et al., Human artificial chromosome (HAC) vector provides long-term therapeutic transgene expression in normal human primary fibroblasts, Gene Ther, 2005;12:852-6.

42. Gothelf A, Hojman P, Gehl J, Therapeutic levels of erythropoietin (EPO) achieved after gene electrotransfer to skin in mice, Gene Ther, 2010;17:1077-84.

43. Cristol JP, BosC JY, Badiou S, et al., Erythropoietin and oxidative stress in haemodialysis: beneficial effects of vitamin E supplementation, Nephrol Dial Transplant. 1997;12:2312-7

44. Cruz DN, De Cal M, Garzotto F, et al., Effect of vitamin $\mathrm{E}$-coated dialysis membranes on anemia in patients with chronic kidney disease: an Italian multicenter study, Int J Artif Organ, 2008;31:545-52.

45. Andrulli S, Di Filippo S, Manzoni C, et al., Effect of synthetic vitamin $\mathrm{E}$-bonded membrane on responsiveness to erythropoiesis-stimulating agents in hemodialysis patients: a pilot study, Nephron Clin Pract, 2010;115:c82-9.

46. Locatelli F, Aljama P, Canaud B, et al., Target haemoglobin to aim for with erythropoiesis-stimulating agents: a position statement by ERBP following publication of the trial to reduce cardiovascular events with Aranesp therapy (TREAT) study, Nephrol Dial Transplant, 2010;25:2846-50.

47. Bohlius J, Schmidlin K, Brillant C, et al., Recombinant human erythropoiesis-stimulating agents and mortality in patients with cancer: a meta-analysis of randomised trials, Lancet, 2009;373:1532-42. 